\title{
CXCR4-directed theranostics in oncology and inflammation
}

\author{
Malte Kircher $^{1} \cdot$ Peter Herhaus $^{2} \cdot$ Margret Schottelius $^{3} \cdot$ Andreas K. Buck $^{1} \cdot$ Rudolf A. Werner $^{1,4}$. \\ Hans-Jürgen Wester ${ }^{3} \cdot$ Ulrich Keller $^{2} \cdot$ Constantin Lapa $^{1}$ (])
}

Received: 7 August 2018 / Accepted: 8 August 2018 / Published online: 13 August 2018

(c) The Author(s) 2018

\begin{abstract}
Given its prominent role in inflammation and cancer biology, the C-X-C motif chemokine receptor 4 (CXCR4) has gained a lot of attention in the recent years. This review gives a short overview of the physiology and pathology of chemokines and chemokine receptors and then focuses on the current experience of targeting CXCR4, using radiolabeled receptor ligands suitable for positron emission tomography (PET) imaging, in both hematologic and solid malignancy as well as in inflammatory conditions. Additionally, CXCR4-directed endoradiotherapy (ERT) as a new treatment option is discussed.
\end{abstract}

Keywords Chemokine $\cdot$ Cancer $\cdot$ Theranostics $\cdot$ Pentixafor $\cdot$ Pentixather

\section{Introduction}

\section{Chemokines and chemokine receptors}

Chemokines are small, secreted proteins that are defined by their structurally important cystein residues, and therefore, grouped, according to the systemic nomenclature from 2000, into four subfamilies, namely $\mathrm{CC}, \mathrm{CXC}, \mathrm{CX}_{3} \mathrm{C}$ and $\mathrm{XC}$ chemokines [1]. Chemokine receptors are named according to their respective ligand (chemokine) and are divided into two groups-conventional chemokine receptors (cCKRs) and atypical chemokine receptors (ACKRs) [2]. cCKRs belong to the family of $\mathrm{G}$ protein-coupled receptors, and therefore, typically signal via the MAPK- and $\beta$-arrestin pathway. ACKRs structurally resemble cCKRs but are not coupled to $\mathrm{G}$ proteins. Therefore, they are mainly involved

Constantin Lapa

lapa_c@ukw.de

1 Department of Nuclear Medicine, University Hospital Würzburg, Oberdürrbacher Str. 6, 97080 Würzburg, Germany

2 Internal Medicine III, Hematology and Medical Oncology, Technische Universität München, Munich, Germany

3 Pharmaceutical Radiochemistry, Technische Universität München, Munich, Germany

4 Division of Nuclear Medicine and Molecular Imaging, Johns Hopkins University School of Medicine, Baltimore, USA in the scavenging and consequently the homeostasis of chemokines [3].

\section{Role of CXCR4 and its ligand CXCL12 in physiology and pathology}

The chemokine receptor CXCR4 is a seven transmembrane $\mathrm{G}$ protein-coupled receptor. CXCR4 is widely expressed throughout the human body during embryonic development and adult life, with uniquely high-expression levels in the hematopoietic system. Its cognate ligand, the chemokine CXCL12 (also named stromal cell-derived factor- $1 \alpha$, SDF- $1 \alpha$ ), is mainly expressed in the bone marrow (BM), lymph nodes, lung, heart, thymus and liver [4]. The canonical CXCR4-CXCL12 axis activates major cellular signaling pathways like RAS-MAPK, PI3K-AKT-mTOR, JAK-STAT and PLC. The $\beta$-arrestin pathway displays a negative feedback loop, leading to CXCR4 internalization and its lysosomal degradation [5].

The outstanding role of the CXCR4-CXCL12 pathway within the chemokine network is emphasized by the fact that either a CXCR4 or CXCL12 deletion, by means of gene knockout, results in embryonic lethality in mice. This reflects the importance of the signaling axis during the development of the hematopoietic, nervous and cardiovascular system [6-8]. Apart from its role in organogenesis, CXCR4-CXCL12 signaling is crucially involved in the homeostasis of the adult hematopoietic system, mainly due to its implication in the retention of hematopoietic 
stem cells in the BM niche [9]. Beyond, it orchestrates an adequate response of the adoptive and innate immune system.

However, the CXCR4 receptor has also been found to be involved in a variety of diseases. For example, it mediates HIV-1 entry into T cells as a co-receptor, where it was first identified [10]. Furthermore, in rheumatoid arthritis, CXCR4-expressing $\mathrm{CD} 4^{+}$memory $\mathrm{T}$ cells accumulate in the inflamed synovium due to the locally increased CXCL12 concentration [11]. In the pathogenesis of atherosclerosis, CXCR4 is involved in the chronic inflammation of the arterial wall which is characterized by a chemokine-mediated influx of leukocytes [12]. CXCR4 has also been identified as a key player in vascular remodeling after injury, atherosclerotic plaque destabilization and aneurysm formation [13]. Moreover, chronic inflammation, and thus local infiltration with CXCR4-expressing immune cells, strongly promotes carcinogenesis of esophageal cancer [14]. Aside from its involvement in various inflammation-related processes, CXCR4 dysregulation was also found to significantly contribute to neurodegenerative diseases [15].

\section{CXCR4-CXCL12 role in cancer}

CXCR4 and CXCL12 play a pivotal role in tumor development and metastasis [16, 17]. This has been demonstrated for a variety of cancer entities, including breast [18], prostate [19, 20], lung [21, 22] and colorectal cancer [23], as well as primary brain tumors such as glioblastoma [24]. Overall, the level of CXCR4 and CXCL12 expression is predictive for the metastatic potential of a given tumor type and mediates organ-specific metastasis [25]. In fact, chemokines are at the center of molecular control of metastasis and tumor growth [26]. By activation of various signaling pathways, e.g., RAS-MAPK, PI3K-AKT-mTOR and JAK-STAT, the CXCL12-CXCR4 axis promotes tumor proliferation, inhibits apoptosis of cancerous cells and facilitates metastasis [27]. CXCL12 modulates the tumor microenvironment by autocrine and paracrine secretion. For instance, the attracted stromal cells are stimulated to secrete growth factors that support tumor proliferation and angiogenesis [27-30]. Further, high CXCL12 levels - via the activation of NF-кBsuppress the production of TNF- $\alpha$ which subsequently leads to a protection of tumor cells from entering apoptosis [31, 32]. In addition, CXCL12 modulates the immune response to the tumor tissue, e.g., by recruiting dendritic cell populations. Those cells tolerate tumor tissue due to a dysfunction in their tumor-associated antigen-presentation to $\mathrm{T}$ cells, thereby promoting immunosuppression within the tumor microenvironment $[33,34]$. Hence, the disruption of the CXCL12-CXCR4 axis provides a promising molecular target for future specific cancer therapies.

\section{Targeting the CXCR4-CXCL12 axis}

Given the undisputed clinical relevance of CXCR4 concerning the growth and spreading of a variety of malignancies, a multitude of CXCR4-directed peptidic and non-peptidic antagonists have been developed during the last decade [16, 28]. Amongst them, the bicyclam AMD3100 (Plerixafor/ Mozobil $^{\mathrm{TM}}$ ) is the only compound that has been approved by the FDA (in 2008) for the mobilization of stem cells and for the treatment of hematological malignancies and other cancers [35-38]. In preclinical mouse models of various malignancies, CXCR4-directed therapies using either alternative small-molecule CXCR4 antagonists such as AMD3465 [39, 40] or MSX-122 [41], peptidic CXCL12 derivatives (CTCE-9908 [42], BKT-140 [43-45], POL-5551 [46-48]), anti-CXCR4-antibodies [49-52] or CXCL12 inhibitors such as the Spiegelmer Nox-A12 [53], have been shown to consistently lead to prolonged overall survival, primarily by effectively preventing distant organ metastasis [54]. Another potent CXCR4 antagonist, LY2510924 (cyclo[Phe-TyrLys(iPr)-D-Arg-2-Nal-Gly-D-Glu]-Lys(iPr)- $\mathrm{NH}_{2}$ ) [55, 56], exhibited high antitumor activities in solid tumor and breast cancer metastatic models and is currently evaluated in phase II clinical trials. Recently, disulfide-bridged cyclic heptapeptide antagonists with excellent in vivo stability $[57,58]$ have been shown to efficiently inhibit lung metastasis in a melanoma model [59], and to reduce the metastatic potential of hepatocellular carcinoma and osteosarcoma in a mouse model [60]. A modified analog (R29, Ac-Arg-Ala-[D-CysArg-Phe-His-Pen]-COOH) efficiently reverts the suppressive activity of T regulatory cells in renal cancer [61]. Lastly, overcoming chemoresistance in AML via RNA-interference within the CXCR4-CXCL12 axis was examined in a human AML xenograft model [62].

\section{Tracer development for diagnosis and therapy}

Based on these developments and to meet the clinical need for pre-therapeutic quantification of CXCR4 expression, intense efforts have also been directed towards the development of suitable CXCR4-targeted molecular imaging agents [63, 64]. Amongst the mentioned CXCR4-targeted antagonists, three classes of compounds have been extensively evaluated with respect to their suitability as in vivo CXCR4 imaging agents:

a. radiolabeled analogs of the bicyclams AMD3100 [6567] and AMD3465 [68-70],

b. ${ }^{18} \mathrm{~F}$ - or ${ }^{68} \mathrm{Ga}$-labeled $\mathrm{T}-140$-based peptides for PET imaging as well as corresponding nuclear/fluorescent ligands for optical/SPECT imaging [71-78], and 
c. radiolabeled, FC-131-based cyclic pentapeptides [7986].

From all three classes, highly promising candidates with high CXCR4 affinity and excellent CXCR4-targeting properties in vitro and in vivo in preclinical studies have emerged, and single representatives such as $\left[{ }^{64} \mathrm{Cu}\right] \mathrm{AMD} 3100$ [65], the T-140 analogue $\left[{ }^{68} \mathrm{Ga}\right]$ NOTA-NFB [74] and the cyclic pentapeptide $\left[{ }^{68} \mathrm{Ga}\right]$ Pentixafor $[80,85]$ have also been evaluated in patients. Unfortunately, the clearance pattern of the first two compounds, both of which exhibit considerable to very high splenic and liver uptake in mice and humans, challenge their applicability for high contrast clinical imaging of CXCR4 expression. In contrast, the FC-131-derived analogue $\left[{ }^{68} \mathrm{Ga}\right]$ Pentixafor cyclo(D-Tyr ${ }^{1}$-D-[NMe]Orn ${ }^{2}$ (AMBS$\left[{ }^{68} \mathrm{Ga}\right]$ DOTA)-Arg $\left.{ }^{3}-\mathrm{Nal}^{4}-\mathrm{Gly}^{5}\right)[79,80,85,87,88]$ shows high affinity and selectivity for human CXCR4, rapid renal excretion, and very low non-specific background accumulation, allowing sensitive and high-contrast PET imaging of CXCR4-expressing tissues in vivo and thus is the only CXCR4-targeted imaging agent that has found broad clinical applicability so far.

Unfortunately, the pronounced sensitivity of the Pentixafor scaffold towards even minor structural modifications [82], that ultimately lead to strongly decreased CXCR4 affinity, precludes the use of its ${ }^{177} \mathrm{Lu}$ - or ${ }^{90} \mathrm{Y}$-labeled version as the corresponding CXCR4-targeted endoradiotherapeutic (ERT) agent within a theranostic concept. Thus, a closely related alternative peptide backbone (cyclo(D-3-iodo$\mathrm{Tyr}^{1}$-D-[NMe]Orn $\left.{ }^{2}-\mathrm{Arg}^{3}-\mathrm{Nal}^{4}-\mathrm{Gly}^{5}\right)$ ) was chosen for the realization of a first CXCR4-targeted endoradiotherapeutic agent, namely Pentixather (cyclo(D-3-iodo-Tyr ${ }^{1}$-D-[NMe] $\mathrm{Orn}^{2}$ (AMBS-DOTA)-Arg ${ }^{3}-\mathrm{Nal}^{4}-\mathrm{Gly}^{5}$ )) [84]. The efficacy and toxicity of Pentixafor/Pentixather-based CXCR4-targeted theranostic approach was demonstrated in patientderived (PDX) and cell line-based xenograft mouse models of ALL and AML [89]. Here, $\left[{ }^{68}\right.$ Ga]Pentixafor PET enabled visualization of CXCR4-positive leukemic burden, and CXCR4-directed ERT with $\left[{ }^{177} \mathrm{Lu}\right]$ Pentixather resulted in the efficient reduction of leukemia in leukemia-harboring tissues (spleen, bone marrow). Despite a substantial in vivo cross-fire effect to the leukemia microenvironment, mesenchymal stem cells subjected to ERT were viable and capable of supporting the growth and differentiation of non-targeted normal hematopoietic cells ex vivo [89].

\section{CXCR4 imaging in oncology}

\section{Imaging hematologic malignancies}

As a likely consequence of its high physiological expression on normal hematopoietic cells, CXCR4 surface levels are also particularly high in several hematologic malignancies, including non-Hodgkin lymphoma (NHL), multiple myeloma (MM), chronic lymphocytic leukemia (CLL) and acute myeloid leukemia (AML), with substantial heterogeneity between diseases and within single entities.

Thus, as a proof-of-concept, the first clinical application of $\left[{ }^{68} \mathrm{Ga}\right]$ Pentixafor for CXCR4-directed PET imaging has been carried out in patients with lymphoproliferative diseases, i.e., NHL and MM [85]. Since then, most experience with $\left[{ }^{68} \mathrm{Ga}\right]$ Pentixafor PET imaging has been gained in patients with MM. In the first disease-specific, proof-ofconcept investigation Philipp-Abbrederis et al. showed that $\left[{ }^{68} \mathrm{Ga}\right]$ Pentixafor PET was able to image disease manifestation in 10/14 patients with MM [90]. These results were confirmed in a larger study by Lapa et al. in which CXCR4 overexpression was shown in lesions of 23/34 MM patients upon CXCR4-targeted PET imaging [91]. Importantly, in both studies, CXCR4-directed PET with $\left[{ }^{68} \mathrm{Ga}\right]$ Pentixafor provided additional information concerning lesion numbers in comparison to $\left[{ }^{18} \mathrm{~F}\right] \mathrm{FDG}$ PET.

Further proof-of-concept studies have shown the clinical applicability of $\left[{ }^{68} \mathrm{Ga}\right]$ Pentixafor in AML and CLL. Herhaus et al. showed that in AML, where the CXCR4-CXCL12 axis is crucially involved in attraction and retention of leukemic cells into the protective BM niche, CXCR4-directed imaging with $\left[{ }^{68} \mathrm{Ga}\right]$ Pentixafor was able to identify patients with CXCR4-positive AML [92]. Another study with $\left[{ }^{68} \mathrm{Ga}\right]$ Pentixafor revealed that BM involvement in CLL patients is associated with a significant tracer uptake when compared to healthy BM [93].

Those studies clearly depict the potential of CXCR4directed PET imaging as a diagnostic marker in hematologic malignancies. However, its application in the future might be more directed towards patient selection for personalized therapeutic concepts such as CXCR4-directed ERT, rather than to evaluate disease extent or analyze remission upon standard treatments. This is partially due to the highly dynamic CXCR4 expression levels that are particularly volatile after administration of chemotherapy [94]. Therefore, the in vivo determination of CXCR4 levels by means of PET outmatches CXCR 4 expression determined by immunochemistry owing to its clinical applicability. In addition, in all the described hematologic malignancies there are either established conventional strategies (cytomorphology, flow cytometry, immunohistochemistry), or molecular markers (serum markers such as immunofixation of monoclonal proteins, or minimal residual disease markers using PCR or sequencing technologies) or an elaborated and wellestablished imaging modality, e.g., $\left[{ }^{18}\right.$ F]FDG PET, for the evaluation or control of remission available.

However, additional utility for response assessment might be found in CXCR4-directed PET imaging of lymphoma of the central nervous system. It is conceivable that in this lymphoma entity, the CXCR4-directed tracer $\left[{ }^{68} \mathrm{Ga}\right]$ Pentixafor, 
due to its better contrast characteristics compared to $\left[{ }^{18} \mathrm{~F}\right]$ FDG PET in the CNS (unpublished data), may improve the current response criteria provided by the International Primary CNS Lymphoma Collaborative Group [95]. It has recently been shown that response assessment with PET/ $\mathrm{CT}$ in a patient with extranodal marginal zone lymphoma of the orbital cavities showed comparable results with $\left[{ }^{68} \mathrm{Ga}\right]$ Pentixafor and $\left[{ }^{18} \mathrm{~F}\right]$ FDG [96].

\section{Imaging solid cancers}

CXCR4 overexpression was also found in various solid cancers, including breast, prostate [18-20], lung and colorectal cancer [21-23]. In analogy with hematologic malignancies, high CXCR4 expression in solid tumors is associated with worse prognosis $[16,97]$. Yet, first in vivo pilot studies with the CXCR4-directed PET tracer $\left[{ }^{68} \mathrm{Ga}\right]$ Pentixafor revealed a more modest as well as heterogeneous, and in some cases absent detectable receptor expression in solid cancers, a finding contrary to the expected CXCR4 expression profile from in vitro studies $[98,99]$. Some solid tumor types, however, did show a pronounced overexpression of CXCR4. Two separate studies found intense, histologically proven CXCR4 expression in most patients with small cell lung cancer [100] as well as non-small cell lung cancer [101]. Furthermore, Bluemel et al. demonstrated feasibility of $\left[{ }^{68} \mathrm{Ga}\right]$ Pentixafor imaging in patients with advanced adrenocortical cancer. In this theranostic approach, about $70 \%$ of patients showed sufficient CXCR 4 expression to potentially qualify for CXCR4-directed radionuclide therapy [102]. A study by Werner et al. looking at the relationship between tumor grading in neuroendocrine tumors and receptor expression found that an increase in receptor expression correlates with higher tumor grade [103]. Furthermore, in a recently published study, Fang et al. showed increased CXCR4 expression in esophageal malignancies, with most of the signal coming from immune cells (neutrophils and T cells), and not esophageal fibroblasts or endothelial cells [14]. This finding adds to earlier observations, describing that neutrophils contributed to carcinogenesis by secretion of interleukins [104]. A first pilot study also demonstrated feasibility of CXCR4-directed imaging for detection of glioblastoma. However, part of the PET signal may not arise from specific binding of the tracer to CXCR4 but might only be a perfusion effect due to a damaged blood-brain barrier [105].

\section{CXCR4 imaging in cardiovascular disease}

Because of its prominent role in inflammation in general, and in immune cell regulation in particular, various studies have investigated the potential of CXCR4-directed imaging for the detection of hidden infectious foci, or its use for visualizing the extent of conditions accompanied by inflammation, respectively. In one study, $\left[{ }^{68} \mathrm{Ga}\right]$ Pentixafor $\mathrm{PET} / \mathrm{CT}$ identified altered cerebral CXCR4 expression in a patient who recently suffered a stroke, corresponding well with ischemia-demarcation as assessed by cerebral MRI [106]. Multiple studies, examining CXCR4 expression after acute myocardial infarction, showed, that the PET signal correlated with the extent of infarcted myocardium, as measured by cardiac MRI [107-110]. In addition, CXCR4 expression might reveal the myocardial healing potential, as assessed by follow-up imaging months after acute myocardial infarction [110]. CXCR4-directed PET imaging has also been successfully used to identify atherosclerotic lesions [111-113]. Most likely, the elevated CXCR4 expression in myocardial infarction and atherosclerotic plaques, as measured by $\left[{ }^{68} \mathrm{Ga}\right]$ Pentixafor PET, originates from infiltrating leukocytes to the infarct area and the atherosclerotic lesion, respectively $[114,115]$. In a recently published study, $\mathrm{Li}$ et al. were able to show anti-inflammatory effects in atherosclerotic lesions of patients that underwent CXCR4-directed ERT [116].

\section{CXCR4 imaging in infectious diseases}

Imaging CXCR4 expression on infiltrating leukocytes might as well be used to track leukocytes that are involved in infectious diseases. In a promising first pilot study, $\left[{ }^{68} \mathrm{Ga}\right]$ Pentixafor PET/CT was able to identify chronic bone infections, with better diagnostic accuracies than anti-granulocyte imaging with ${ }^{99 \mathrm{~m}} \mathrm{Tc}$-besilesomab, or ${ }^{99 \mathrm{~m}} \mathrm{Tc}$-labeled white blood cells, respectively [117]. Results of another study indicate, that CXCR4-directed PET/MRI with $\left[{ }^{68} \mathrm{Ga}\right]$ Pentixafor is able to detect infectious foci by imaging leukocyte infiltration in patients with complicated urinary tract infections after kidney transplantation [118].

\section{Theranostics}

As mentioned before, most tumors have a worsening prognosis with increasing CXCR4 expression [119], although many of the underlying mechanisms and their implications for disease progression are still unknown. For instance, high CXCR4 expression on AML blasts correlates with a poor prognosis $[99,120]$, and the protective bone marrow environment is considered a major reason for treatment resistance and relapse [121], suggesting potential benefits from CXCR4-directed therapies.

Imaging of CXCR4 expression in oncology has mostly not been of diagnostic nature until now. Instead, it was guided predominantly by theranostic thinking, in pursuit of potential therapeutic remedies for patients with otherwise limited or non-existent treatment alternatives. 


\section{CXCR4-targeted radionuclide therapy}

Pentixather, the therapeutic twin of Pentixafor, is a promising CXCR4 ligand that can be labeled with radionuclides for ERT [84]. First studies examined the use of Pentixather, labeled with beta-emitters ${ }^{177} \mathrm{Lu}$ or ${ }^{90} \mathrm{Y}$, for ERT of advanced stage MM patients. Although initial response rates were high and adverse effects were limited, overall survival in this very high-risk cohort was not extended $[105,122]$. Other pilot investigations showed encouraging results using ERT with $\left[{ }^{177} \mathrm{Lu}\right] /\left[{ }^{90} \mathrm{Y}\right]$ Pentixather in diffuse large B cell lymphoma (DLBCL; see also Fig. 1) [123] and in AML patients, respectively [89]. As of now, there is only one prospective trial for CXCR4-directed ERT in preparation (COLPRIT trial, Eudra-CT 2015-001817-28), that will primarily investigate the tolerable dose and side effects of such ERT in patients with MM or lymphoma.

In all cases until now, ERT was performed in addition to high-dose chemotherapy regimens, followed by subsequent hematopoietic stem cell transplantation. It is noteworthy that in hematologic diseases with the intent to perform allogeneic hematopoietic transplantation, the myeloablation by ERT is considered a desired effect to

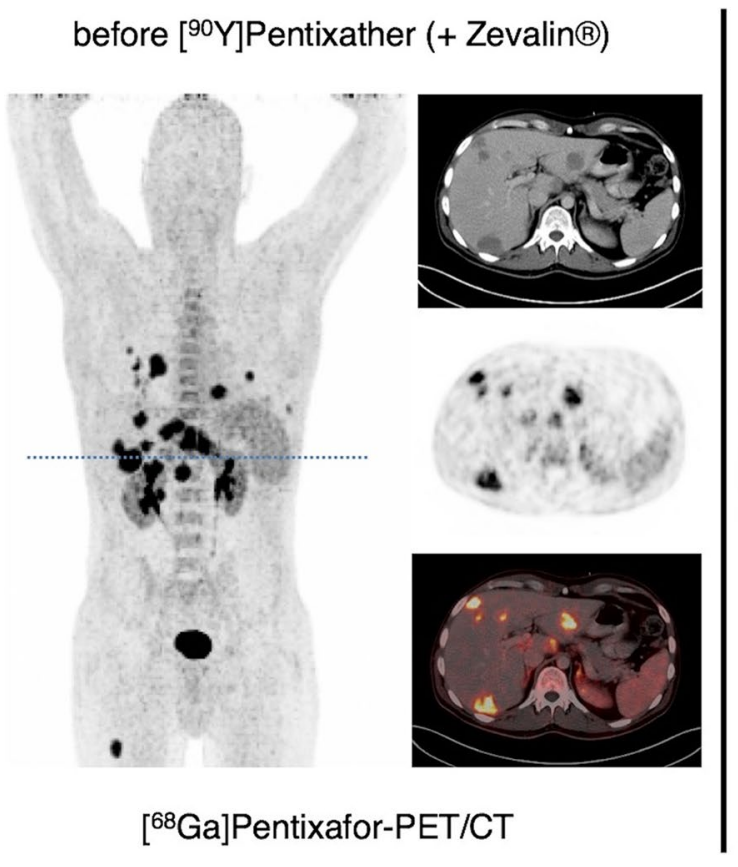

Fig. 1 Example of CXCR4-directed endoradiotherapy with $\left[{ }^{90} \mathrm{Y}\right] \mathrm{Pen}-$ tixather (in combination with CD20-directed radioimmunotherapy with $\left.\left[{ }^{90} \mathrm{Y}\right] \mathrm{Zevalin}{ }^{\circledR}\right)$ as part of the conditioning regimen prior to allogeneic stem cell transplantation in relapsed/refractory diffuse large $\mathrm{B}$ cell lymphoma (DLBCL). Display of maximum intensity projections (outer columns) and transaxial slices (inner columns; CT, upper row, PET, middle row; PET/CT, lower row) of pre-therapeutic CXCR4directed and post-therapeutic $\left[{ }^{18} \mathrm{~F}\right] \mathrm{FDG}$ PET/CT. Post-therapeutic allow engraftment of the cellular therapeutic. Opposite to that, allogeneic hematopoietic cell transplantation is not an established and suitable approach in other malignancies, and myeloablation induced by binding of the radionuclide to hematopoietic progenitor cells in the bone marrow is certainly of major concern. ERT without stem cell rescue might be technically feasible for tumors with pronounced receptor overexpression as witnessed in adrenocortical cancer or small cell lung cancer but requires further development and prospective investigations.

\section{Outlook}

CXCR4-directed ERT, and particularly-imaging- is rapidly gaining popularity at a few academic centers. The (pre-)clinically observed dynamics in CXCR4 expression (e.g., chemotherapy-induced) present new opportunities to potentially modulate CXCR4 expression and function. By prior receptor upregulation, imaging might benefit from higher sensitivities, and anti-cancer therapies might find more targets on the cell surface for a stronger effect. Similarly, downregulation of CXCR4 might have synergistic effects with conventional therapies. Furthermore, labeling a

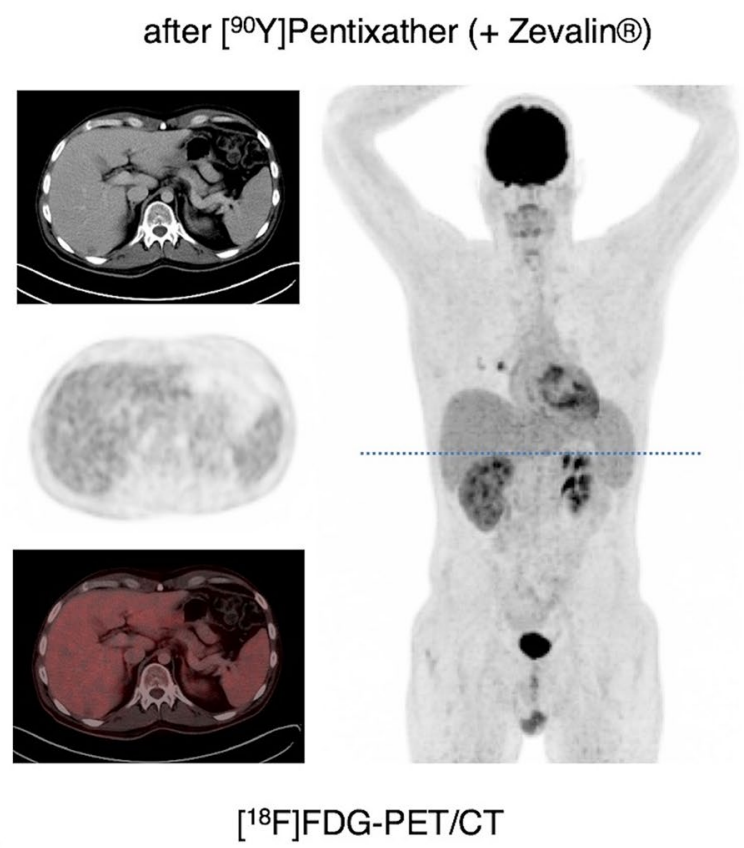

imaging was performed 8 weeks after administration of $3.7 \mathrm{GBq}$ of $\left[{ }^{90} \mathrm{Y}\right]$ Pentixather, $1.2 \mathrm{GBq}$ of $\left[{ }^{90} \mathrm{Y}\right] \mathrm{Zevalin}{ }^{\circledR}$ as well as conditioning chemotherapy with subsequent repeat stem cell transplantation (SCT) and demonstrated partial response with residual yet vital pulmonary lesions and resolution of all hepatic and nodal DLBCL manifestations. DLBCL had been relapsed from prior first allogeneic SCT and been refractory to all chemotherapeutic regimens 
CXCR4 ligand with an alpha-emitter for ERT might present a breakthrough in hematologic malignancies, as the higher energy transfer would lead to more effective destruction of cancer and cancer-supporting cells.

\section{Summary}

CXCR4 and its natural ligand, the chemokine CXCL12, play important physiologic roles in embryonic development, hematopoiesis and immunity. But the CXCR4-CXCL12 axis is also deeply associated with disease and is particularly involved in tumor growth and metastasis. A multitude of different malignancies overexpress CXCR4 on their respective cell surface, which predominantly is associated with a worse prognosis. Different therapeutics targeting CXCR4 or its ligand CXCL12 have been developed. For instance, Plerixafor, the first FDA-approved CXCR4 inhibitor, mobilizes stem-/progenitor cells from the bone marrow into the circulation. Subsequently, various CXCR4-directed imaging tracers were developed, with the positron-emitting PET tracer $\left[{ }^{68} \mathrm{Ga}\right]$ Pentixafor being the most frequently used today. CXCR4 imaging with $\left[{ }^{68} \mathrm{Ga}\right]$ Pentixafor has successfully been performed in several different malignancies, as well as in cardiovascular disease and infections. Its therapeutic twin, Pentixather, labeled with the beta-emitters ${ }^{177} \mathrm{Lu}$ or ${ }^{90} \mathrm{Y}$, has already been used for ERT in various hematologic malignancies. Research in the field of CXCR4-directed imaging and radionuclide therapy is highly active, and new developments over the full spectrum of translational medicine are anticipated in the coming years.

Acknowledgements HJ Wester is the founder and shareholder of Scintomics. All other authors declare no conflict of interests.

Open Access This article is distributed under the terms of the Creative Commons Attribution 4.0 International License (http://creativeco mmons.org/licenses/by/4.0/), which permits unrestricted use, distribution, and reproduction in any medium, provided you give appropriate credit to the original author(s) and the source, provide a link to the Creative Commons license, and indicate if changes were made.

\section{References}

1. Murphy PM, Baggiolini M, Charo IF, Hebert CA, Horuk R, Matsushima K, et al. International union of pharmacology. XXII. Nomenclature for chemokine receptors. Pharmacol Rev. 2000;52(1):145-76.

2. Bachelerie F, Ben-Baruch A, Burkhardt AM, Combadiere C, Farber JM, Graham GJ, et al. International Union of Basic and Clinical Pharmacology. [corrected]. LXXXIX. Update on the extended family of chemokine receptors and introducing a new nomenclature for atypical chemokine receptors. Pharmacol Rev. 2014;66(1):1-79.
3. Hughes CE, Nibbs RJB. A guide to chemokines and their receptors. FEBS J. 2018.

4. Juarez J, Bendall L, Bradstock K. Chemokines and their receptors as therapeutic targets: the role of the SDF-1/CXCR4 axis. Curr Pharm Des. 2004;10(11):1245-59.

5. Pawig L, Klasen C, Weber C, Bernhagen J, Noels H. Diversity and inter-connections in the CXCR4 chemokine receptor/ligand family: molecular perspectives. Front Immunol. 2015;6:429.

6. Nagasawa T, Hirota S, Tachibana K, Takakura N, Nishikawa S, Kitamura Y, et al. Defects of B-cell lymphopoiesis and bonemarrow myelopoiesis in mice lacking the CXC chemokine PBSF/ SDF-1. Nature. 1996;382(6592):635-8.

7. Tachibana K, Hirota S, Iizasa H, Yoshida H, Kawabata K, Kataoka Y, et al. The chemokine receptor CXCR4 is essential for vascularization of the gastrointestinal tract. Nature. 1998;393(6685):591-4.

8. Zou YR, Kottmann AH, Kuroda M, Taniuchi I, Littman DR. Function of the chemokine receptor CXCR4 in haematopoiesis and in cerebellar development. Nature. 1998;393(6685):595-9.

9. Karpova D, Bonig H. Concise review: CXCR4/CXCL12 signaling in immature hematopoiesis-lessons from pharmacological and genetic models. Stem Cells. 2015;33(8):2391-9.

10. Feng Y, Broder CC, Kennedy PE, Berger EA. HIV-1 entry cofactor: functional cDNA cloning of a seven-transmembrane, G protein-coupled receptor. Science. 1996;272(5263):872-7.

11. Nagafuchi Y, Shoda H, Sumitomo S, Nakachi S, Kato R, Tsuchida Y, et al. Immunophenotyping of rheumatoid arthritis reveals a linkage between HLA-DRB1 genotype, CXCR4 expression on memory CD4(+) T cells, and disease activity. Sci Rep. 2016;6:29338.

12. Galkina E, Ley K. Immune and inflammatory mechanisms of atherosclerosis (*). Annu Rev Immunol. 2009;27:165-97.

13. Schober A, Bernhagen J, Weber C. Chemokine-like functions of MIF in atherosclerosis. J Mol Med (Berl). 2008;86(7):761-70.

14. Fang HY, Munch NS, Schottelius M, Ingermann J, Liu H, Schauer M, et al. CXCR4 is a potential target for diagnostic PET/ CT imaging in Barrett's Dysplasia and Esophageal adenocarcinoma. Clin Cancer Res. 2018;24(5):1048-61.

15. Bonham LW, Karch CM, Fan CC, Tan C, Geier EG, Wang Y, et al. CXCR4 involvement in neurodegenerative diseases. Transl Psychiatry. 2018;8(1):73.

16. Domanska UM, Kruizinga RC, Nagengast WB, Timmer-Bosscha H, Huls G, de Vries EG, et al. A review on CXCR4/CXCL12 axis in oncology: no place to hide. Eur J Cancer. 2013;49(1):219-30.

17. Burger JA, Kipps TJ. CXCR4: a key receptor in the crosstalk between tumor cells and their microenvironment. Blood. 2006;107(5):1761-7.

18. Williams SA, Harata-Lee Y, Comerford I, Anderson RL, Smyth MJ, McColl SR. Multiple functions of CXCL12 in a syngeneic model of breast cancer. Mol Cancer. 2010;9:250.

19. Arya M, Patel HR, McGurk C, Tatoud R, Klocker H, Masters J, et al. The importance of the CXCL12-CXCR4 chemokine ligandreceptor interaction in prostate cancer metastasis. J Exp Ther Oncol. 2004:4(4):291-303.

20. Darash-Yahana M, Pikarsky E, Abramovitch R, Zeira E, Pal B, Karplus R, et al. Role of high expression levels of CXCR4 in tumor growth, vascularization, and metastasis. FASEB J. 2004;18(11):1240-2.

21. Su L, Zhang J, Xu H, Wang Y, Chu Y, Liu R, et al. Differential expression of CXCR4 is associated with the metastatic potential of human non-small cell lung cancer cells. Clin Cancer Res. 2005;11(23):8273-80.

22. Phillips RJ, Burdick MD, Lutz M, Belperio JA, Keane MP, Strieter RM. The stromal derived factor-1/CXCL12-CXC chemokine receptor 4 biological axis in non-small cell lung cancer metastases. Am J Respir Crit Care Med. 2003;167(12):1676-86. 
23. Speetjens FM, Liefers GJ, Korbee CJ, Mesker WE, van de Velde CJ, van Vlierberghe RL, et al. Nuclear localization of CXCR4 determines prognosis for colorectal cancer patients. Cancer Microenviron. 2009;2(1):1-7.

24. Terasaki M, Sugita Y, Arakawa F, Okada Y, Ohshima K, Shigemori M. CXCL12/CXCR4 signaling in malignant brain tumors: a potential pharmacological therapeutic target. Brain Tumor Pathol. 2011;28(2):89-97.

25. Müller A, Homey B, Soto H, Ge N, Catron D, Buchanan ME, et al. Involvement of chemokine receptors in breast cancer metastasis. Nature. 2001;410(6824):50-6.

26. Zlotnik A, Burkhardt AM, Homey B. Homeostatic chemokine receptors and organ-specific metastasis. Nat Rev Immunol. 2011;11(9):597-606.

27. Guo F, Wang Y, Liu J, Mok SC, Xue F, Zhang W. CXCL12/ CXCR4: a symbiotic bridge linking cancer cells and their stromal neighbors in oncogenic communication networks. Oncogene. 2016;35(7):816-26.

28. Scala S. Molecular pathways: targeting the CXCR4-CXCL12 axis-untapped potential in the tumor microenvironment. Clin Cancer Res. 2015;21(19):4278-85.

29. Orimo A, Gupta PB, Sgroi DC, Arenzana-Seisdedos F, Delaunay T, Naeem R, et al. Stromal fibroblasts present in invasive human breast carcinomas promote tumor growth and angiogenesis through elevated SDF-1/CXCL12 secretion. Cell. 2005;121(3):335-48.

30. Muller A, Homey B, Soto H, Ge N, Catron D, Buchanan ME, et al. Involvement of chemokine receptors in breast cancer metastasis. Nature. 2001;410(6824):50-6.

31. Wang CY, Mayo MW, Baldwin AS. Jr. TNF- and cancer therapyinduced apoptosis: potentiation by inhibition of NF-kappaB. Science. 1996;274(5288):784-7.

32. Helbig G, Christopherson KW 2nd, Bhat-Nakshatri P, Kumar $\mathrm{S}$, Kishimoto $\mathrm{H}$, Miller KD, et al. NF-kappaB promotes breast cancer cell migration and metastasis by inducing the expression of the chemokine receptor CXCR4. J Biol Chem. 2003;278(24):21631-8.

33. Kryczek I, Wei S, Keller E, Liu R, Zou W. Stroma-derived factor (SDF-1/CXCL12) and human tumor pathogenesis. Am J Physiol Cell Physiol. 2007;292(3):C987-95.

34. Zou W. Immunosuppressive networks in the tumour environment and their therapeutic relevance. Nat Rev Cancer. 2005;5(4):263-74.

35. Brave M, Farrell A, Ching Lin S, Ocheltree T, Pope Miksinski S, Lee SL, et al. FDA review summary: Mozobil in combination with granulocyte colony-stimulating factor to mobilize hematopoietic stem cells to the peripheral blood for collection and subsequent autologous transplantation. Oncology. 2010;78(3-4):282-8.

36. Herrmann K, Lapa C, Wester HJ, Schottelius M, Schiepers C, Eberlein U, et al. Biodistribution and radiation dosimetry for the chemokine receptor CXCR4-targeting probe $68 \mathrm{Ga}$-pentixafor. J Nucl Med. 2015;56(3):410-6.

37. Taromi S, Kayser G, Catusse J, von Elverfeldt D, Reichardt W, Braun F, et al. CXCR4 antagonists suppress small cell lung cancer progression. Oncotarget. 2016;7(51):85185-95.

38. Ma Q, Jones D, Borghesani PR, Segal RA, Nagasawa T, Kishimoto $\mathrm{T}$, et al. Impaired B-lymphopoiesis, myelopoiesis, and derailed cerebellar neuron migration in CXCR4- and SDF-1-deficient mice. Proc Natl Acad Sci USA. 1998;95(16):9448-53.

39. Bodart V, Anastassov V, Darkes MC, Idzan SR, Labrecque J, Lau $\mathrm{G}$, et al. Pharmacology of AMD3465: a small molecule antagonist of the chemokine receptor CXCR4. Biochem Pharmacol. 2009;78(8):993-1000.

40. Ling X, Spaeth E, Chen Y, Shi Y, Zhang W, Schober W, et al. The CXCR4 antagonist AMD3465 regulates oncogenic signaling and invasiveness in vitro and prevents breast cancer growth and metastasis in vivo. PLoS One. 2013;8(3):e58426.

41. Liang Z, Zhan W, Zhu A, Yoon Y, Lin S, Sasaki M, et al. Development of a unique small molecule modulator of CXCR4. PLoS One. 2012;7(4):e34038.

42. Wong D, Kandagatla P, Korz W, Chinni SR. Targeting CXCR4 with CTCE-9908 inhibits prostate tumor metastasis. BMC Urol. 2014;14:12.

43. Beider K, Darash-Yahana M, Blaier O, Koren-Michowitz M, Abraham M, Wald $\mathrm{H}$, et al. Combination of imatinib with CXCR4 antagonist BKT140 overcomes the protective effect of stroma and targets CML in vitro and in vivo. Mol Cancer Ther. 2014;13(5):1155-69.

44. Fahham D, Weiss ID, Abraham M, Beider K, Hanna W, Shlomai $Z$, et al. In vitro and in vivo therapeutic efficacy of CXCR4 antagonist BKT140 against human non-small cell lung cancer. J Thorac Cardiovasc Surg. 2012;144(5):1167-75 e1.

45. Peled A, Abraham M, Avivi I, Rowe JM, Beider K, Wald $\mathrm{H}$, et al. The high-affinity CXCR4 antagonist BKT140 is safe and induces a robust mobilization of human CD34 + cells in patients with multiple myeloma. Clin Cancer Res. 2014;20(2):469-79.

46. Karpova D, Dauber K, Spohn G, Chudziak D, Wiercinska E, Schulz M, et al. The novel CXCR4 antagonist POL5551 mobilizes hematopoietic stem and progenitor cells with greater efficiency than Plerixafor. Leukemia. 2013;27(12):2322-31.

47. Sison EA, Magoon D, Li L, Annesley CE, Romagnoli B, Douglas GJ, et al. POL5551, a novel and potent CXCR4 antagonist, enhances sensitivity to chemotherapy in pediatric ALL. Oncotarget. 2015;6(31):30902-18.

48. Xiang J, Hurchla MA, Fontana F, Su X, Amend SR, Esser AK, et al. CXCR4 protein epitope mimetic antagonist POL5551 disrupts metastasis and enhances chemotherapy effect in triplenegative breast cancer. Mol Cancer Ther. 2015;14(11):2473-85.

49. Azad BB, Chatterjee S, Lesniak WG, Lisok A, Pullambhatla M, Bhujwalla ZM, et al. A fully human CXCR4 antibody demonstrates diagnostic utility and therapeutic efficacy in solid tumor xenografts. Oncotarget. 2016;7(11):12344-58.

50. Peng S-B, Zhang X, Paul D, Kays LM, Ye M, Vaillancourt P, et al. Inhibition of CXCR4 by LY2624587, a fully humanized anti-CXCR4 antibody induces apoptosis of hematologic malignancies. PloS one. 2016;11(3):e0150585.

51. Broussas M, Boute N, Akla B, Berger S, Beau-Larvor C, Champion $\mathrm{T}$, et al. A new anti-CXCR4 antibody that blocks the CXCR4/SDF-1 axis and mobilizes effector cells. Mol Cancer Ther. 2016;15(8):1890-9.

52. Kuhne MR, Mulvey T, Belanger B, Chen S, Pan C, Chong C, et al. BMS-936564/MDX-1338: a fully human anti-CXCR4 antibody induces apoptosis in vitro and shows antitumor activity in vivo in hematologic malignancies. Clin Cancer Res. 2013;19(2):357-66.

53. Duda DG, Kozin SV, Kirkpatrick ND, Xu L, Fukumura D, Jain RK. CXCL12 (SDF1alpha)-CXCR4/CXCR7 pathway inhibition: an emerging sensitizer for anticancer therapies? Clin Cancer Res. 2011;17(8):2074-80.

54. Ramsey DM, McAlpine SR. Halting metastasis through CXCR4 inhibition. Bioorg Med Chem Lett. 2013;23(1):20-5.

55. Cho BS, Zeng Z, Mu H, Wang Z, Konoplev S, McQueen T, et al. Antileukemia activity of the novel peptidic CXCR4 antagonist LY2510924 as monotherapy and in combination with chemotherapy. Blood. 2015;126(2):222-32.

56. Peng SB, Zhang X, Paul D, Kays LM, Gough W, Stewart J, et al. Identification of LY2510924, a novel cyclic peptide CXCR4 antagonist that exhibits antitumor activities in solid tumor and breast cancer metastatic models. Mol Cancer Ther. 2015;14(2):480-90. 
57. Di Maro S, Di Leva FS, Trotta AM, Brancaccio D, Portella L, Aurilio M, et al. Structure-activity relationships and biological characterization of a novel, potent, and serum stable C-X-C chemokine receptor type 4 (CXCR4) antagonist. J Med Chem. 2017;60(23):9641-52.

58. Di Maro S, Trotta AM, Brancaccio D, Di Leva FS, La Pietra $\mathrm{V}$, Ierano C, et al. Exploring the N-Terminal Region of C-X-C Motif chemokine 12 (CXCL12): Identification of plasma-stable cyclic peptides as novel, potent $\mathrm{C}-\mathrm{X}$-C chemokine receptor type 4 (CXCR4) antagonists. J Med Chem. 2016;59(18):8369-80.

59. Ierano C, Portella L, Lusa S, Salzano G, D'Alterio C, Napolitano $\mathrm{M}$, et al. CXCR4-antagonist Peptide R-liposomes for combined therapy against lung metastasis. Nanoscale. 2016;8(14):7562-71.

60. Fontanella R, Pelagalli A, Nardelli A, D'Alterio C, Ierano C, Cerchia L, et al. A novel antagonist of CXCR4 prevents bone marrow-derived mesenchymal stem cell-mediated osteosarcoma and hepatocellular carcinoma cell migration and invasion. Cancer Lett. 2016;370(1):100-7.

61. Santagata S, Napolitano M, D'Alterio C, Desicato S, Maro $\mathrm{SD}$, Marinelli L, et al. Targeting CXCR4 reverts the suppressive activity of T-regulatory cells in renal cancer. Oncotarget. 2017;8(44):77110-20.

62. Chen Y, Jacamo R, Konopleva M, Garzon R, Croce C, Andreeff M. CXCR4 downregulation of let-7a drives chemoresistance in acute myeloid leukemia. J Clin Investig. 2013;123(6):2395-407.

63. Weiss ID, Jacobson O. Molecular imaging of chemokine receptor CXCR4. Theranostics. 2013;3(1):76-84.

64. George GPC, Pisaneschi F, Quang-De N, Aboagye EO. Positron emission tomographic imaging of CXCR4 in cancer: challenges and promises. Mol Imaging. 2015;14.

65. Jacobson O, Weiss ID, Szajek L, Farber JM, Kiesewetter DO. 64Cu-AMD3100 - a novel imaging agent for targeting chemokine receptor CXCR4. Bioorg Med Chem. 2009;17(4):1486-93.

66. Nimmagadda S, Pullambhatla M, Stone K, Green G, Bhujwalla ZM, Pomper MG. Molecular imaging of CXCR4 receptor expression in human cancer xenografts with [64Cu]AMD3100 positron emission tomography. Cancer Res. 2010;70(10):3935-44.

67. Hartimath SV, Domanska UM, Walenkamp AM, Rudi AJOD, de Vries EF. [(9)(9)mTc]O(2)-AMD3100 as a SPECT tracer for CXCR4 receptor imaging. Nucl Med Biol. 2013;40(4):507-17.

68. De Silva RA, Peyre K, Pullambhatla M, Fox JJ, Pomper MG, Nimmagadda S. Imaging CXCR4 expression in human cancer xenografts: evaluation of monocyclam 64Cu-AMD3465. J Nucl Med. 2011;52(6):986-93.

69. Hartimath SV, Khayum MA, van Waarde A, Dierckx R, de Vries EFJ. $N$-[(11)C]methyl-AMD3465 PET as a tool for in vivo measurement of chemokine receptor 4 (CXCR4) occupancy by therapeutic drugs. Mol Imaging Biol. 2017;19(4):570-7.

70. Hartimath SV, van Waarde A, Dierckx RA, de Vries EF. Evaluation of $N$-[(11)C]methyl-AMD3465 as a PET tracer for imaging of CXCR4 receptor expression in a C6 glioma tumor model. Mol Pharm. 2014;11(11):3810-7.

71. George GP, Stevens E, Åberg O, Nguyen Q-D, Pisaneschi F, Spivey AC, et al. Preclinical evaluation of a CXCR4-specific 68 Ga-labelled TN14003 derivative for cancer PET imaging. Bioorg Med Chem. 2014;22(2):796-803.

72. Yan X, Niu G, Wang Z, Yang X, Kiesewetter DO, Jacobson O, et al. Al [18F] NOTA-T140 peptide for noninvasive visualization of CXCR4 Expression. Mol Imaging Biol. 2015:1-8.

73. Jacobson O, Weiss ID, Kiesewetter DO, Farber JM, Chen X. PET of tumor CXCR4 expression with 4-18F-T140. J Nucl Med. 2010;51(11):1796-804.

74. Wang Z, Zhang M, Wang L, Wang S, Kang F, Li G, et al. Prospective study of (68)Ga-NOTA-NFB: radiation dosimetry in healthy volunteers and first application in glioma patients. Theranostics. 2015;5(8):882-9.
75. Buckle T, van Berg NS, Kuil J, Bunschoten A, Oldenburg J, Borowsky AD, et al. Non-invasive longitudinal imaging of tumor progression using an (111)indium labeled CXCR4 peptide antagonist. Am J Nucl Med Mol Imaging. 2012;2(1):99-109.

76. Kuil J, Buckle T, Oldenburg J, Yuan H, Borowsky AD, Josephson $\mathrm{L}$, et al. Hybrid peptide dendrimers for imaging of chemokine receptor 4 (CXCR4) expression. Mol Pharm. 2011;8(6):2444-53.

77. Kuil J, Buckle T, Yuan H, van den Berg NS, Oishi S, Fujii N, et al. Synthesis and evaluation of a bimodal CXCR4 antagonistic peptide. Bioconjug Chem. 2011;22(5):859-64.

78. Nishizawa K, Nishiyama H, Oishi S, Tanahara N, Kotani H, Mikami Y, et al. Fluorescent imaging of high-grade bladder cancer using a specific antagonist for chemokine receptor CXCR4. Int J Cancer. 2010;127(5):1180-7.

79. Demmer O, Gourni E, Schumacher U, Kessler H, Wester HJ. PET imaging of CXCR4 receptors in cancer by a new optimized ligand. ChemMedChem. 2011;6(10):1789-91.

80. Gourni E, Demmer O, Schottelius M, D’Alessandria C, Schulz S, Dijkgraaf I, et al. PET of CXCR4 expression by a (68)Galabeled highly specific targeted contrast agent. J Nucl Med. 2011;52(11):1803-10.

81. Poschenrieder A, Schottelius M, Osl T, Schwaiger M, Wester HJ. $[(64) \mathrm{Cu}]$ NOTA-pentixather enables high resolution PET imaging of CXCR4 expression in a preclinical lymphoma model. EJNMMI Radiopharm Chem. 2017;2(1):2.

82. Poschenrieder A, Schottelius M, Schwaiger M, Kessler H, Wester HJ. The influence of different metal-chelate conjugates of pentixafor on the CXCR4 affinity. EJNMMI Res. 2016;6(1):36.

83. Poschenrieder A, Schottelius M, Schwaiger M, Wester HJ. Preclinical evaluation of [(68)Ga]NOTA-pentixafor for PET imaging of CXCR4 expression in vivo - a comparison to [(68)Ga] pentixafor. EJNMMI Res. 2016;6(1):70.

84. Schottelius M, Osl T, Poschenrieder A, Hoffmann F, Beykan S, Hanscheid H, et al. [(177)Lu]pentixather: comprehensive preclinical characterization of a first CXCR4-directed endoradiotherapeutic agent. Theranostics. 2017;7(9):2350-62.

85. Wester HJ, Keller U, Schottelius M, Beer A, Philipp-Abbrederis $\mathrm{K}$, Hoffmann F, et al. Disclosing the CXCR4 expression in lymphoproliferative diseases by targeted molecular imaging. Theranostics. 2015;5(6):618-30.

86. George GP, Pisaneschi F, Stevens E, Nguyen QD, Aberg O, Spivey AC, et al. Scavenging strategy for specific activity improvement: application to a new CXCR4-specific cyclopentapeptide positron emission tomography tracer. J Labelled Comp Radiopharm. 2013;56(13):679-85.

87. Demmer O, Dijkgraaf I, Schottelius M, Wester H-J, Kessler H. Introduction of functional groups into peptides via $N$-alkylation. Organic Lett. 2008;10(10):2015-8.

88. Demmer O, Dijkgraaf I, Schumacher U, Marinelli L, Cosconati $\mathrm{S}$, Gourni E, et al. Design, synthesis, and functionalization of dimeric peptides targeting chemokine receptor CXCR4. J Med Chem. 2011;54(21):7648-62.

89. Habringer S, Lapa C, Herhaus P, Schottelius M, Istvanffy R, Steiger K, et al. Dual targeting of acute leukemia and supporting niche by CXCR4-directed theranostics. Theranostics. 2018;8(2):369-83.

90. Philipp-Abbrederis K, Herrmann K, Knop S, Schottelius M, Eiber M, Luckerath $\mathrm{K}$, et al. In vivo molecular imaging of chemokine receptor CXCR4 expression in patients with advanced multiple myeloma. EMBO Mol Med. 2015;7(4):477-87.

91. Lapa C, Schreder M, Schirbel A, Samnick S, Kortum KM, Herrmann K, et al. [(68)Ga]Pentixafor-PET/CT for imaging of chemokine receptor CXCR4 expression in multiple myelomacomparison to [(18)F]FDG and laboratory values. Theranostics. 2017;7(1):205-12. 
92. Herhaus P, Habringer S, Philipp-Abbrederis K, Vag T, Gerngross $\mathrm{C}$, Schottelius M, et al. Targeted positron emission tomography imaging of CXCR4 expression in patients with acute myeloid leukemia. Haematologica. 2016;101(8):932-40.

93. Mayerhoefer ME, Jaeger U, Staber P, Raderer M, Wadsak W, Pfaff S, et al. [68Ga]Ga-pentixafor PET/MRI for CXCR4 imaging of chronic lymphocytic leukemia: preliminary results. Invest Radiol. 2018.

94. Lapa C, Luckerath K, Kircher S, Hanscheid H, Grigoleit GU, Rosenwald A, et al. Potential influence of concomitant chemotherapy on CXCR4 expression in receptor directed endoradiotherapy. Br J Haematol. 2018.

95. Abrey LE, Batchelor TT, Ferreri AJ, Gospodarowicz M, Pulczynski EJ, Zucca E, et al. Report of an international workshop to standardize baseline evaluation and response criteria for primary CNS lymphoma. J Clin Oncol. 2005;23(22):5034-43.

96. Herhaus P, Habringer S, Vag T, Steiger K, Slotta-Huspenina $\mathrm{J}$, Gerngross C, et al. Response assessment with the CXCR4directed positron emission tomography tracer [(68)Ga]Pentixafor in a patient with extranodal marginal zone lymphoma of the orbital cavities. EJNMMI Res. 2017;7(1):51.

97. Kaemmerer D, Reimann C, Specht E, Wirtz RM, Sayeg M, Baum $\mathrm{RP}$, et al. Differential expression and prognostic value of the chemokine receptor CXCR4 in bronchopulmonary neuroendocrine neoplasms. Oncotarget. 2015;6(5):3346-58.

98. Vag T, Gerngross C, Herhaus P, Eiber M, Philipp-Abbrederis $\mathrm{K}$, Graner FP, et al. First experience with chemokine receptor CXCR4-targeted PET imaging of patients with solid cancers. J Nucl Med. 2016;57(5):741-6.

99. Lapa C, Kircher S, Schirbel A, Rosenwald A, Kropf S, Pelzer T, et al. Targeting CXCR4 with [(68)Ga]Pentixafor: a suitable theranostic approach in pleural mesothelioma? Oncotarget. 2017;8(57):96732-7.

100. Lapa C, Luckerath K, Rudelius M, Schmid JS, Schoene A, Schirbel A, et al. [68Ga]Pentixafor-PET/CT for imaging of chemokine receptor 4 expression in small cell lung cancer - initial experience. Oncotarget. 2016.

101. Derlin T, Jonigk D, Bauersachs J, Bengel FM. Molecular imaging of chemokine receptor CXCR4 in non-small cell lung cancer using $68 \mathrm{Ga}$-pentixafor PET/CT: comparison with 18F-FDG. Clin Nucl Med. 2016;41(4):e204-5.

102. Bluemel C, Hahner S, Heinze B, Fassnacht M, Kroiss M, Bley TA, et al. Investigating the chemokine receptor 4 as potential theranostic target in adrenocortical cancer patients. Clin Nucl Med. 2017;42(1):e29-34.

103. Werner RA, Weich A, Higuchi T, Schmid JS, Schirbel A, Lassmann $\mathrm{M}$, et al. Imaging of chemokine receptor 4 expression in neuroendocrine tumors-a triple tracer comparative approach. Theranostics. 2017;7(6):1489-98.

104. Quante M, Bhagat G, Abrams JA, Marache F, Good P, Lee MD, et al. Bile acid and inflammation activate gastric cardia stem cells in a mouse model of Barrett-like metaplasia. Cancer Cell. 2012;21(1):36-51.

105. Herrmann K, Schottelius M, Lapa C, Osl T, Poschenrieder A, Hanscheid H, et al. First-in-human experience of CXCR4directed endoradiotherapy with $177 \mathrm{Lu}-$ and $90 \mathrm{Y}$-labeled pentixather in advanced-stage multiple myeloma with extensive intra- and extramedullary disease. J Nucl Med. 2016;57(2):248-51.

106. Schmid JS, Schirbel A, Buck AK, Kropf S, Wester HJ, Lapa C. [68Ga]Pentixafor-positron emission tomography/computed tomography detects chemokine receptor CXCR4 expression after ischemic stroke. Circ Cardiovasc Imaging. 2016;9(9):e005217.

107. Lapa C, Reiter T, Werner RA, Ertl G, Wester HJ, Buck AK, et al. [(68)Ga]pentixafor-PET/CT for imaging of chemokine receptor 4 expression after myocardial infarction. JACC Cardiovasc Imaging. $2015 ; 8(12): 1466-8$.

108. Thackeray JT, Derlin T, Haghikia A, Napp LC, Wang Y, Ross TL, et al. Molecular imaging of the chemokine receptor CXCR4 after acute myocardial infarction. JACC Cardiovasc Imaging. 2015;8(12):1417-26.

109. Rischpler C, Nekolla SG, Kossmann H, Dirschinger RJ, Schottelius M, Hyafil F, et al. Upregulated myocardial CXCR4-expression after myocardial infarction assessed by simultaneous GA-68 pentixafor PET/MRI. J Nucl Cardiol. 2016;23(1):131-3.

110. Reiter T, Kircher M, Schirbel A, Werner RA, Kropf S, Ertl $\mathrm{G}$, et al. Imaging of C-X-C motif chemokine receptor CXCR4 expression after myocardial infarction with $[(68) \mathrm{Ga}]$ PentixaforPET/CT in correlation with cardiac MRI. JACC Cardiovasc Imaging. 2018.

111. Hyafil F, Pelisek J, Laitinen I, Schottelius M, Mohring M, Doring $\mathrm{Y}$, et al. Imaging the cytokine receptor CXCR4 in atherosclerotic plaques with the radiotracer (68)Ga-Pentixafor for PET. J Nucl Med. 2017;58(3):499-506.

112. Li X, Heber D, Leike T, Beitzke D, Lu X, Zhang X, et al. [68Ga] Pentixafor-PET/MRI for the detection of Chemokine receptor 4 expression in atherosclerotic plaques. Eur J Nucl Med Mol Imaging. 2017.

113. Weiberg D, Thackeray JT, Daum G, Sohns JM, Kropf S, Wester $\mathrm{HJ}$, et al. Clinical molecular imaging of chemokine receptor CXCR4 expression in atherosclerotic plaque using (68) Gapentixafor PET: correlation with cardiovascular risk factors and calcified plaque burden. J Nucl Med. 2018;59(2):266-72.

114. Nahrendorf M, Swirski FK, Aikawa E, Stangenberg L, Wurdinger $\mathrm{T}$, Figueiredo JL, et al. The healing myocardium sequentially mobilizes two monocyte subsets with divergent and complementary functions. J Exp Med. 2007;204(12):3037-47.

115. Nahrendorf M, Swirski FK. PET imaging of leukocytes in patients with acute myocardial infarction. JACC Cardiovasc Imaging. 2015;8(12):1427-9.

116. Li X, Kemmer L, Zhang X, Kircher M, Buck AK, Wester HJ, et al. Anti-inflammatory effects on atherosclerotic lesions induced by CXCR4-directed endoradiotherapy. J Am Coll Cardiol. 2018;72(1):122-3.

117. Bouter C, Meller B, Sahlmann CO, Staab W, Wester HJ, Kropf S, et al. (68)Ga-pentixafor PET/CT imaging of chemokine receptor CXCR4 in chronic infection of the bone: first insights. J Nucl Med. 2018;59(2):320-6.

118. Derlin T, Gueler F, Brasen JH, Schmitz J, Hartung D, Herrmann TR, et al. Integrating MRI and chemokine receptor CXCR4-targeted PET for detection of leukocyte infiltration in complicated urinary tract infections after kidney transplantation. J Nucl Med. 2017;58(11):1831-7.

119. Lapa C, Schirbel A, Samnick S, Luckerath K, Kortum KM, Knop $\mathrm{S}$, et al. The gross picture: intraindividual tumour heterogeneity in a patient with nonsecretory multiple myeloma. Eur J Nucl Med Mol Imaging. 2017;44(6):1097-8.

120. Spoo AC, Lubbert M, Wierda WG, Burger JA. CXCR4 is a prognostic marker in acute myelogenous leukemia. Blood. 2007;109(2):786-91.

121. Laurenzana I, Lamorte D, Trino S, De Luca L, Ambrosino C, Zoppoli P, et al. Extracellular vesicles: a new prospective in crosstalk between microenvironment and stem cells in hematological malignancies. Stem Cells Int. 2018;2018:9863194.

122. Lapa C, Herrmann K, Schirbel A, Hanscheid H, Luckerath K, Schottelius M, et al. CXCR4-directed endoradiotherapy induces high response rates in extramedullary relapsed Multiple Myeloma. Theranostics. 2017;7(6):1589-97.

123. Lapa C, Hanscheid H, Kircher M, Schirbel A, Wunderlich G, Werner R, et al. Feasibility of CXCR4-directed radioligand therapy in advanced diffuse large B cell lymphoma. J Nucl Med. 2018. 